\title{
Validity of peak expiratory flow measurement in assessing reversibility of airflow obstruction
}

\author{
Friedo W Dekker, Agnes C Schrier, Peter J Sterk, Joop H Dijkman
}

\begin{abstract}
Background Assessing the reversibility of airflow obstruction by peak expiratory (PEF) measurements would be practicable in general practice, but its usefulness has not been investigated.

Methods PEF measurements were performed (miniWright peak flow meter) in 73 general practice patients (aged 40 to 84) with a history of asthma or chronic obstructive lung disease before and after $400 \mu \mathrm{g}$ inhaled salbutamol. The change in PEF was compared with the change in forced expiratory volume in one second $\left(F_{E V}\right)$. Reversible airflow obstruction was analysed in two ways according to previous criteria. When defined as a $9 \%$ or greater increase in $\mathrm{FEV}_{1}$ expressed as a percentage of predicted values reversibility was observed in $42 \%$ of patients. Relative operating characteristic analysis showed that an absolute improvement in PEF of $601 / \mathrm{min}$ or more gave optimal discrimination between patients with reversible and irreversible airflow obstruction (the sensitivity and specificity of an increase of $60 \mathrm{1} / \mathrm{min}$ in detecting a $9 \%$ or more increase in $\mathrm{FEV}_{1}$ as a percentage of predicted values were $68 \%$ and $93 \%$ respectively, with a positive predictive value of $87 \%$ ). When defined as an increase of $190 \mathrm{ml}$ or more in $\mathrm{FEV}_{1}$, reversible airflow obstruction was observed in $53 \%$ of patients. Again an absolute improvement in PEF of 60 $1 /$ min or more gave optimal discrimination between patients with reversible and irreversible airflow obstruction (sensitivity $56 \%$, specificity $94 \%$, and positive predictive value $92 \%$ ).

Conclusion Absolute changes in PEF can be used as a simple technique to diagnose reversible airflow obstruction in patients from general practice.
\end{abstract}

Departments of

General Practice and Pulmonology,

University of Leiden, Leiden,

The Netherlands

F W Dekker

A C Schrier

P J Sterk

J H Dijkman

Address for correspondence: Dr F W Dekker,

Department of General

Practice, PO Box 2088,

2301 CB Leiden,

The Netherlands.

Accepted 15 November 1991 reversible component in their airflow obst tion. ${ }^{45}$ Assessment of the presence and degree of reversibility of airflow obstruction is clinically important, particularly in elderly patients with asthma or chronic obstructive lung disease. ${ }^{6}$
There is increasing evidence that reversibility of airflow obstruction occurs in patients with chronic obstructive lung disease as well those with asthma. ${ }^{1-3}$ Several studies have shown that some patients with chronic obstructive lung disease show a substantial
Most patients with asthma or chronic obstructive lung disease are looked after by a general practitioner. In this setting a simple, reliable, and cheap method is needed to assess the severity of obstruction and its degree of reversibility. The measurement of peak expiratory flow (PEF) potentially meets these criteria. PEF within and between subjects correlates moderately well with the forced expiratory volume in one second $\left(F_{E V}\right)$ obtained by spirometry. ${ }^{7}$ Hence assessing reversibility with a peak flow meter could be useful in the screening and follow up of patients with asthma or chronic obstructive lung disease. Although the use of the peak flow meter is widely advocated, ${ }^{89}$ we are not aware of data on the validity of peak flow measurements in assessing reversibility of airflow obstruction in patients with asthma or chronic obstructive lung disease. We compared PEF and $\mathrm{FEV}_{1}$ in assessing reversibility of airflow obstruction in middle aged and elderly patients with asthma or chronic obstructive lung disease and developed a practical criterion for assessing the presence of reversibility in general practice.

\section{Patients and methods}

Patients were recruited from three general practices in a health care centre responsible for 10000 people near to Leiden University Hospital. The selection of patients was based on the requirement to obtain a representative population of patients from general practice with a broad range of airflow obstruction and reversibility. Patients were asked to participate in the study if they were $\mathbf{4 0}$ or more, known to the general practitioner as having a history of asthma or chronic obstructive lung disease (regardless of presenting symptoms), and had been prescribed treatment for lung disease (bronchodilators, cromoglycate, or steroids) in the 12 months preceding the study. ${ }^{10}$ They were asked to visit the surgery to complete a questionnaire on medical history, based on the questionnaire of the British Medical Research Council and the European Community for Coal and Steel. ${ }^{11}$ Inhaled treatment for lung disease was withheld for eight hours before the visit and theophyllines were withheld for 48 hours. $F_{E V}$ and the inspiratory vital capacity (IVC) were measured with a calibrated rolling seal spirometer (Mijnhardt Volugraph 2000) and peak expiratory flow (PEF) by a miniWright peak flow meter, according to recommendations. ${ }^{12}$ For all lung function measurements the largest of three satisfactory 
Table 1 Patient characteristics $(n=73)$. Values are numbers of patients or means (SD) with ranges

\begin{tabular}{|c|c|c|}
\hline $\begin{array}{l}\text { Age (years) } \\
\text { Men }\end{array}$ & $\begin{array}{l}61 \cdot 9(12 \cdot 8) \\
36\end{array}$ & $40 \cdot 0-84 \cdot 0$ \\
\hline \multicolumn{3}{|l|}{ Smoking state: } \\
\hline Current smoker & 24 & \\
\hline Ex-smoker & 27 & \\
\hline Pulmonary treatment & 49 & \\
\hline \multicolumn{3}{|l|}{ Corticosteroids } \\
\hline Inhaled & 20 & \\
\hline Oral & 4 & \\
\hline Treated by lung specialist & 15 & \\
\hline \multicolumn{3}{|l|}{$\mathrm{FEV}_{1}$ : } \\
\hline Litres & $\begin{aligned} & 1.88(0.89) \\
& 70.7(26.7)\end{aligned}$ & $\begin{array}{r}0.58-4.45 \\
20.4-118.0\end{array}$ \\
\hline FEV $_{1} /$ IVC ( $\%$ pred $)$ & $78 \cdot 1(22 \cdot 5)$ & $26 \cdot 5-125 \cdot 1$ \\
\hline \multicolumn{3}{|l|}{ Increase in $\mathbf{F E V}_{1}$ after bronchodilator: } \\
\hline Litres & $0 \cdot 29(0 \cdot 30)$ & $-0.03-1 \cdot 38$ \\
\hline $\begin{array}{l}\% \text { predicted values } \\
\% \text { above baseline values }\end{array}$ & $\begin{array}{l}10.6(10 \cdot 1) \\
20.3(28.6)\end{array}$ & $\begin{array}{l}-1 \cdot 1-42 \cdot 9 \\
-1 \cdot 0-166 \cdot 7\end{array}$ \\
\hline \multicolumn{3}{|l|}{ PEF (1/min): } \\
\hline Baseline & $344(130)$ & $100-630$ \\
\hline Increase after bronchodilator & $41(42)$ & $-40-160$ \\
\hline
\end{tabular}

$\mathrm{FEV}_{1}=$ forced expiratory volume in one second; IVC = inspiratory vital capacity; PEF = peak expiratory flow. did not differ significantly. Airflow obstruction was present in 46 of the 73 patients (an $\mathrm{FEV}_{1}$ or $\mathrm{FEV}_{1}$ to IVC ratio, or both, below the $90 \%$ confidence interval of predicted values ${ }^{12}$ ).

\section{REVERSIBILITY}

The distribution of the degree of reversibility for each variable is shown in figure 1 . The mean (SD) increase in $\mathrm{FEV}_{1}$ as a percentage of predicted values was $10 \cdot 6 \%(10 \cdot 1 \%)$ (table 1 ). Twenty four of the 46 patients with airflow obstruction (52\%) showed a reversibility of $9 \%$ or more in predicted $\mathrm{FEV}_{1}$. Reversibility, whether expressed as a percentage of predicted values or as an absolute increase in $\mathrm{FEV}_{1}$, correlated negatively with age $(r=-0.36$, $\mathrm{p}=0.002 ; \mathrm{r}=-0.52, \mathrm{p}=0.000$, respectively) but did not correlate significantly with $\mathrm{FEV}_{1}(\mathrm{ml})$ before bronchodilator $(\mathrm{r}=-0.13$, $\mathrm{p}=0.28 ; \mathrm{r}=0.02, \mathrm{p}=0.87$, respectively). Ten of the 34 patients over 65 showed a reversibility of $9 \%$ or more in FEV, expressed as a percentage of predicted values and 10 showed a reversibility of $190 \mathrm{ml}$ or more in FEV $_{1}$.

The mean (SD) increase in PEF as a percentage of predicted values was $10 \cdot 2 \%(11 \cdot 1 \%)$. The correlation between the change in PEF and change in $\mathrm{FEV}_{1}$ was $0.67(\mathrm{p}<0.001)$.

With an increase in $\mathrm{FEV}_{1}$ of $9 \%$ of predicted values as the measure of reversibility a plot was constructed of sensitivity and specificity against

from a metered dose inhaler connected to a reservoir attachment (Nebuhaler). ${ }^{13}$ Two measures of reversibility of airflow obstruction were used: $(a)$ an increase after bronchodilator of $9 \%$ or more in $\mathrm{FEV}_{1}$ expressed as a percentage of predicted values ${ }^{14}$ and $(b)$ an absolute increase of $190 \mathrm{ml}$ or more in $\mathrm{FEV}_{1}{ }^{15}$ PEF reversibility was expressed as the absolute change in $1 / \mathrm{min}$ after bronchodilator. Sensitivity and specificity of PEF reversibility was analysed at different cut off points (relative operating characteristic analysis) for both measures of reversibility. ${ }^{16}$

\section{ANALYSIS}

Participants were compared with nonparticipants with respect to age, sex, prescribed treatment for lung disease, and the number of patients referred to a lung specialist by means of $\chi^{2}$ and Student's $t$ tests. Spearman rank correlations were calculated between reversibility, $\mathrm{FEV}_{1}$ before bronchodilator, and age. All significance levels are two tailed.

\section{Results}

Of the 123 patients who met the inclusion criteria, seven were excluded because of a concomitant disorder and six because the general practitioner considered it too burdensome for them to participate; one person died before the start of the study. Of the remaining 109 patients, 73 were willing and able to visit the surgery (table 1). Patients participating in the study were older than those who did not $(t=3.38 ; \mathrm{df}=107 ; \mathrm{p}<0.01)$ and more had been prescribed treatment for lung disease $\left(\chi^{2}=4.25 ; \mathrm{df}=1 ; \mathrm{p}<0.05\right)$. The sex and number of patients referred to a lung specialist
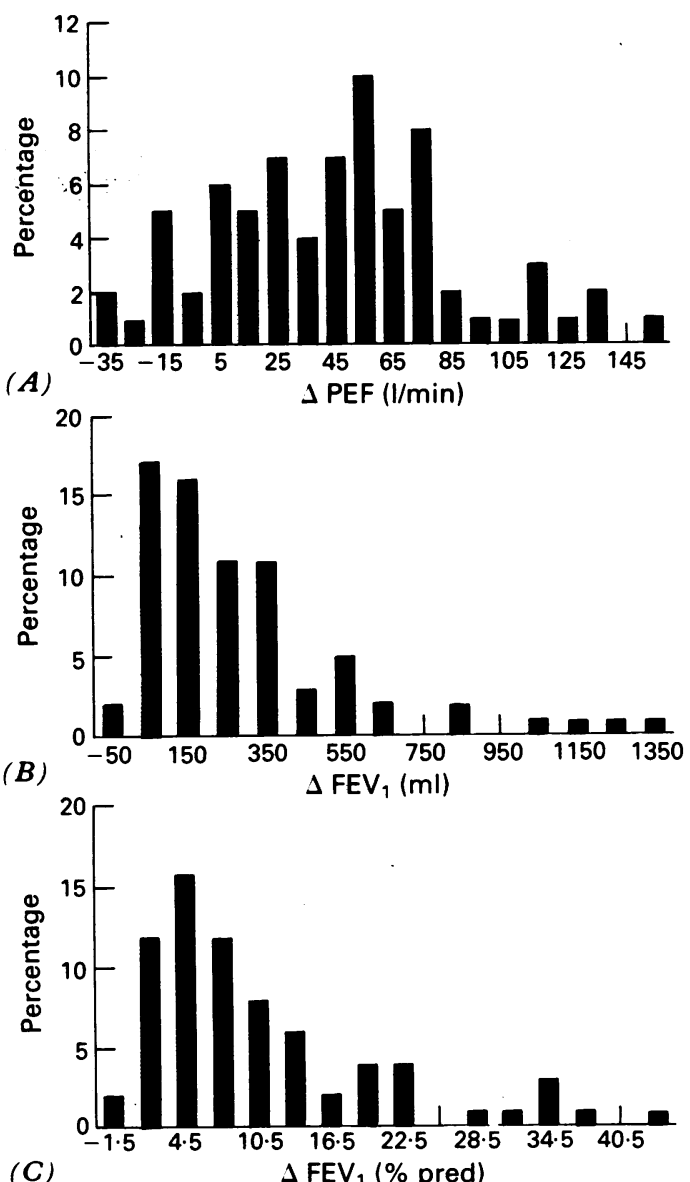

Figure 1 Relative distribution of bronchodilator response expressed as $(A)$ absolute change in peak expiratory flow (PEF), (B) absolute change in $F E V_{1}$, and $(C)$ change in $F E V$, as a percentage of predicted values. 
Figure 2 Sensitivity and specificity of absolute improvement in peak expiratory flow (PEF) Measures of reversibility are $(A)$ increase in FEV $\geqslant 9 \%$ of predicted values and $(B)$ increase in $F E V$ $\geqslant 190 \mathrm{ml}$
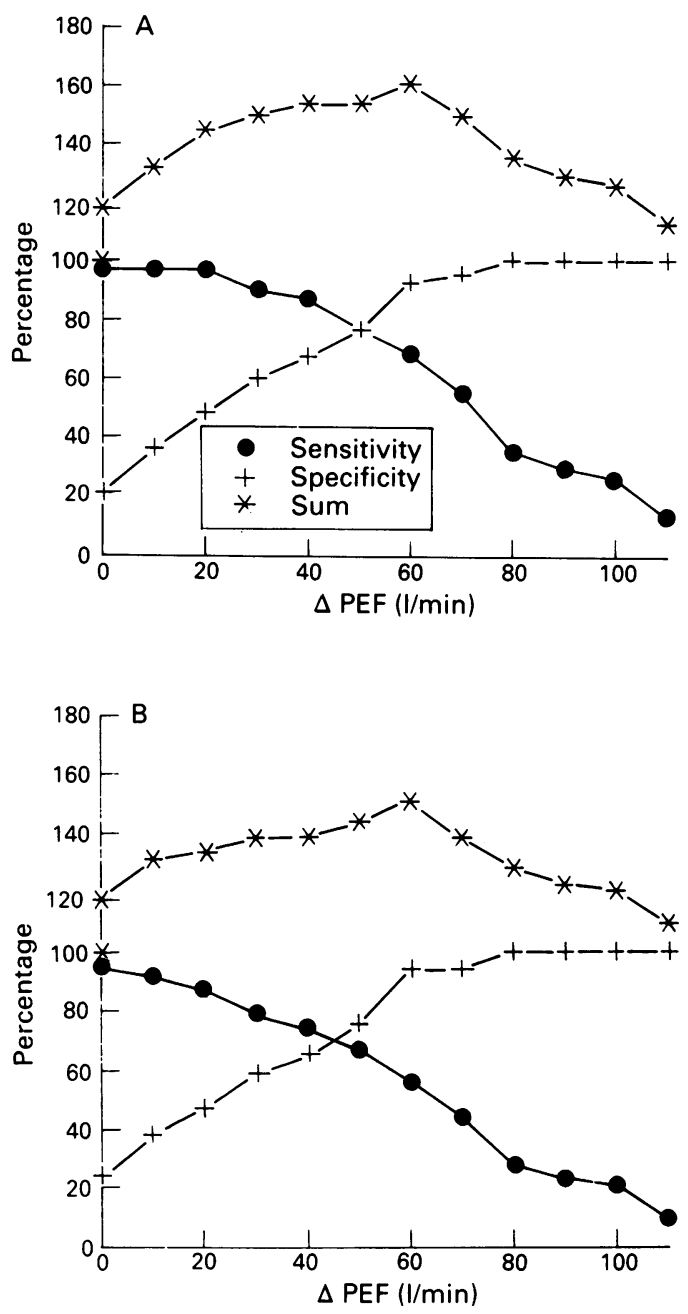

absolute PEF increase (figure 2). The sum of sensitivity and specificity was at its highest at a cut off point of an increase in PEF of $601 / \mathrm{min}$ (sensitivity $68 \%$, specificity $93 \%$; table 2 ). The same cut off point was found with an absolute improvement in $\mathrm{FEV}_{1}$ of $190 \mathrm{ml}$ as the measure of reversibility (sensitivity $56 \%$, specificity $94 \%$; figure 2). A lower cut off point results in higher sensitivities but lower specificities. For example, in figure 2(A) a cut off point of $401 / \mathrm{min}$ results in a sensitivity of $87 \%$ and a specificity of $67 \%$ (positive predictive value $66 \%$, negative predictive value $87 \%$ ).

Table 2 Sensitivity, specificity, and predictive values of absolute improvement in peak expiratory flow $(P E F)$ after $400 \mu \mathrm{g}$ salbutamol

\begin{tabular}{|c|c|c|c|c|c|c|}
\hline \multirow[b]{3}{*}{ Improvement in PEF (l/min) } & \multicolumn{6}{|c|}{ Improvement in $F E V_{1}$} \\
\hline & \multicolumn{3}{|c|}{$\%$ predicted values } & \multicolumn{3}{|c|}{ Absolute (ml) } \\
\hline & $\geqslant 9$ & $<9$ & Total & $\geqslant 190$ & $<190$ & Total \\
\hline \multirow[t]{2}{*}{$\begin{array}{l}\geqslant 60 \\
<60 \\
\text { Total }\end{array}$} & $\begin{array}{l}21 \\
10 \\
31\end{array}$ & $\begin{array}{r}3 \\
39 \\
42\end{array}$ & $\begin{array}{l}24 \\
49 \\
73\end{array}$ & $\begin{array}{l}22 \\
17 \\
39\end{array}$ & $\begin{array}{r}2 \\
32 \\
34\end{array}$ & $\begin{array}{l}24 \\
49 \\
73\end{array}$ \\
\hline & \multicolumn{3}{|c|}{$\begin{array}{lr}\text { Sensitivity } & 67 \cdot 7 \% \\
\text { Specificity } & 92.9 \% \\
\text { Positive } & \\
\text { predictive value } 87.5 \% \\
\text { Negative } \\
\text { predictive value } 79.6 \%\end{array}$} & \multicolumn{2}{|c|}{$\begin{array}{l}\text { Sensitivity } \\
\text { Specificity } \\
\text { Positive } \\
\text { predictive valu } \\
\text { Negative } \\
\text { predictive valu }\end{array}$} & $\begin{array}{r}56.4 \% \\
94.1 \% \\
\quad \text { e } 91.7 \%\end{array}$ \\
\hline
\end{tabular}

\section{Discussion}

In this study in elderly patients in general practice with a history of asthma or chronic obstructive lung disease the prevalence of reversible airflow obstruction was $42 \cdot 5-53.4 \%$, depending on whether the criterion of Dales $e t$ al $\left(9 \%\right.$ or more increase in $\mathrm{FEV}_{1}$ as a percentage of predicted values) ${ }^{14}$ or Tweeddale et al (increase in $\mathrm{FEV}_{1}$ of $190 \mathrm{ml}$ or more) ${ }^{15}$ was used. After $400 \mu \mathrm{g}$ inhaled salbutamol the predictive value of an increase in PEF of $60 \mathrm{l} / \mathrm{min}$ or more was respectively $87.5 \%$ and $91.7 \%$ in detecting an improvement in $\mathrm{FEV}_{1}$ of $9 \%$ or more of predicted values or an increase of $190 \mathrm{ml}$ or more. These results show the importance and feasibility of assessing the reversibility of airflow obstruction in general practice with a simple technique.

The effect of possible selection bias or methodological errors has been considered. Firstly, as we studied a general practice population selected on the basis of a history of asthma or chronic obstructive lung disease, our results will hold for screening only these types of patients. This population is an important one, however, and will include the majority of patients with asthma or chronic obstructive lung disease as they are treated only by general practitioners. ${ }^{17}$ The group as a whole is probably representative of a typical heterogeneous population of patients with asthma or chronic obstructive lung disease treated in general practice. This approach makes our population to some extent comparable with those of Sourk et al, who studied bronchodilator response in a heterogeneous group of patients referred to a pulmonary function laboratory. ${ }^{18}$

Secondly, no attempt was made to discriminate between patients with asthma or chronic obstructive lung disease. The diagnostic label may be of minor importance, the response to treatment being the guiding principle, at least in general practice. ${ }^{19} 20$

Thirdly, our findings obviously depend on the measure of reversibility that we used. Various criteria for clinically relevant reversibility have been proposed recently (table 3). Tweeddale et al found that the absolute increase in $\mathrm{FEV}_{1}$ correlated less well with baseline $F E V_{1}$ than did the percentage increase in $\mathrm{FEV}_{1}{ }^{15}$ Dales et al found that the increase in $\mathrm{FEV}_{1}$ when expressed as a percentage of predicted values showed little relation to baseline $\mathrm{FEV}_{1}$ and was remarkably stable with sex, age, and height. ${ }^{14}$ This finding is supported by the work of Eliasson $e t a l^{21}$ and more recently by that of Weir and Burge. ${ }^{22}$ These findings strongly suggest that increase in $\mathrm{FEV}_{1}$ expressed as a percentage of predictive values or as an absolute increase in $\mathrm{FEV}_{1}$ are better ways of expressing reversibility of airflow obstruction than increase in FEV $\mathrm{F}_{1}$ expressed as a percentage of baseline $\mathrm{FEV}_{1}$. In our analysis the results were highly comparable with either measure of reversibility in $\mathrm{FEV}_{1}-9 \%$ of predicted values or $190 \mathrm{ml}$.

Fourthly, the optimal cut off point for PEF reversibility was derived from the point at which the sum of sensitivity and specificity was 
Table 3 Some recently developed criteria for reversibility of airflow obstruction

\begin{tabular}{|c|c|c|c|c|}
\hline Reference & Population & Agent & Analysis & Criterion $\left(F E V_{1}\right)$ \\
\hline Sourk et al $1983^{18}$ & $\begin{array}{l}40 \text { patients referred } \\
\text { to a pulmonary } \\
\text { function } \\
\text { laboratory (mean } \\
\text { baseline } \text { FEV }_{1} \\
60 \% \text { of predicted } \\
\text { values) }\end{array}$ & Placebo & $\begin{array}{l}\text { Upper limit of } 95 \% \\
\text { confidence } \\
\text { interval }\end{array}$ & $\begin{array}{l}12 \cdot 3 \% \text { increase above } \\
\text { prebronchodilator values } \\
\text { or } 178 \mathrm{ml}\end{array}$ \\
\hline Tweeddale et al $1984^{15}$ & $\begin{array}{l}54 \text { healthy subjects } \\
\text { and } 13 \text { patients } \\
\text { with restrictive } \\
\text { ventilatory } \\
\text { defects }\end{array}$ & Natural variability & $\begin{array}{l}\text { One tailed upper } \\
\text { limit of } 95 \% \\
\text { confidence } \\
\text { interval }\end{array}$ & $190 \mathrm{ml}$ \\
\hline Dales et al $1988^{14}$ & $\begin{array}{l}2609 \text { subjects } \\
\text { without } \\
\text { symptoms } \\
\text { (FEV } 1>80 \% \\
\text { predicted values) }\end{array}$ & Terbutaline $500 \mu \mathrm{g}$ & 95th Centile & $\begin{array}{l}9 \% \text { predicted values (or } \\
9 \% \text { increase above } \\
\text { prebronchodilator values } \\
\text { or } 291 \mathrm{ml} \text { ) }\end{array}$ \\
\hline
\end{tabular}

at its highest, thus giving equal weight to both variables. ${ }^{16}$ From a clinical point of view a high sensitivity might be more important than a high specificity. A lower cut off point could therefore be chosen based on the relative operating characteristic curves in figure 2 , although this will result in a lower specificity and some loss of positive predictive value.

Finally, we do not have data on the repeatability of a PEF response to a bronchodilator. Data on the repeatability of bronchodilator responses would be hard to interpret because of the unknown relative contributions of random errors and the expected real biological variation in this population. The repeatability of the PEF itself is known to be not much worse than the repeatability of $\mathrm{FEV}_{1} \cdot{ }^{23}$ As the repeatability of the criteria of Dales $e t$ al and Tweeddale $e t$ al are not known either, this subject deserves future attention.

The moderate correlation between improvement in PEF and $\mathrm{FEV}_{1}$ is not unexpected. Although these two indices of pulmonary function are determined by somewhat different physiological mechanisms, ${ }^{24}$ the relation between single measurements of PEF and $\mathrm{FEV}_{1}$ is good. ${ }^{7}$ Our results suggest that the bronchodilating effect of a $\beta$ adrenergic agent can be documented by either variable. There are some limitations, however, in using PEF to detect reversible airflow obstruction, as defined by our "gold standard" improvement in $\mathrm{FEV}_{1}$. The criterion of a $60 \mathrm{l} / \mathrm{min}$ or more increase in PEF was highly specific but not so sensitive. This means that a smaller increase in PEF does not exclude reversible airflow obstruction-for example, using a criterion of an increase in PEF of $40 \mathrm{l} / \mathrm{min}$ or more results in a sensitivity of $87 \%$ in detecting a reversibility of $\mathrm{FEV}_{1}$ of $9 \%$ or more of predicted values and $74 \%$ in detecting a reversibility of FEV $190 \mathrm{ml}$ or more. Failure of the $\mathrm{FEV}_{1}$ to respond to a bronchodilator on a single occasion does not imply that the patient has irreversible airflow obstruction, as emphasised previously. ${ }^{25}$ Some patients who do not show bronchodilatation as judged by a peakflow measurement may have partially reversible airflow obstruction which would have been detected by the $\mathrm{FEV}_{1}$ or at a follow up visit after appropriate treatment by either PEF or FEV . $_{\text {. }}$
Our findings have clinical implications for general practice. Previous criteria for reversibility of airflow obstruction have mainly concerned the $\mathrm{FEV}_{1}$. We have shown that reversibility of airflow obstruction in patients with asthma or chronic obstructive lung disease can be assessed by means of simple PEF measurements and give comparable results to those obtained by $\mathrm{FEV}_{1}$. The criterion of an absolute increase in PEF of $60 \mathrm{l} / \mathrm{min}$ avoids having to make any calculations and seems to be an excellent way of predicting reversibility.

As the prevalence of reversibility of airflow obstruction in our population was between $40 \%$ and $50 \%$, we recommend bronchodilator testing with a peak flow meter in general practice. Potentially reversible airway obstruction is often overlooked or misdiagnosed in elderly patients, ${ }^{6}$ and we have found asthma to be undertreated in general practice. ${ }^{26}$ Patients with asthma or chronic obstructive lung disease in general practice may benefit from a trial with bronchodilators. ${ }^{27}$ The peak flow meter is a useful diagnostic tool in diagnosing reversibility of airflow obstruction with a high predictive value in patients in general practice who are $\mathbf{4 0}$ or more and have a history of asthma or chronic obstructive lung disease. This could help to improve the quality of care given by general practitioners to patients with asthma or chronic obstructive lung disease.

1 American Thoracic Society. Standards for the diagnosis and care of patients with chronic obstructive pulmonary disease (COPD) and asthma. Am Rev Respir Dis 1987; 136:225-43.

2 Gross NJ. COPD: a disease of reversible airflow obstruction. Am Rev Respir Dis 1986;133:725-6.

3 Drazen JM, Gerard C. Reversing the reversible. $N$ Engl J Med 1989;320:1555-6.

4 Anthonisen NR, Wright EC, and the IPPB Trial Group. Bronchodilator response in chronic obstructive pulmonary disease. Am Rev Respir Dis 1986;133:814-9.

5 Guyatt GH, Townsend M, Pugsley SO, et al. Bronchodilators in chronic airflow limitation. Am Rev Respir Dis 1987;135:1069-74.

6 Baneriee DK, Lee GS, Malik K, Daly S. Underdiagnosis of asthma in the elderly. British Journal of Diseases of the Chest 1987;81:23-9.

7 Kelly CA, Gibson GJ. Relation between FEV and peak $_{1}$ expiratory flow in patients with chronic airflow obstruction. Thorax 1988;43:335-6.

$8 \mathrm{Gregg} \mathrm{I}$. The quality of care of asthma in general practice-a challenge for the future. Fam Pract 1985;2:94-100.

9 Katz DN. The mini-Wright peak flow meter for evaluating airway obstruction in family practice. J Fam Pract 1983;17:51-7.

10 Gellert AR, Gellert SL, Iliffe SR. Prevalence and man- 
agement of asthma in a London inner city general practice. Br J Gen Pract 1990;40:197-201.

11 Lende $\mathrm{R}$ van der, Orie NGM. The MRC-ECCS questionnaire on respiratory symptoms. Use in epidemiology. Scandinavian Journal of Respiratory Diseases 1972;53:218-26.

12 Quanjer PH, ed. Standardized lung function testing. Bull Eur Physiopathol Respir 1983;19 suppl 5.

13 Newman SP, Millar AB, Lennard-Jones TR, Morén F, Clarke SW. Improvement of pressurised aerosol deposition with Nebuhaler spacer device. Thorax 1984;39:93541.

14 Dales RE, Spitzer WO, Tousignant $P$, Schechter M, Suissa $S$. Clinical interpretation of airway response to a bronchodilator. Am Rev Respir Dis 1988;138:317-20.

15 Tweeddale PM, Merchant S, Leslie M, Alexander F, McHardy GJR. Short term variability in $\mathrm{FEV}_{1}$ : relation to McHardy GJR. Short term variability in $\mathrm{FEV}_{1}$ : relation to
pretest activity, level of $\mathrm{FEV}_{1}$, and smoking habits. Thorax 1984;39:928-32.

16 Beck JR, Colice GL. Relative operating characteristic analysis applied to tests of pulmonary function. Seminars in Respiratory Medicine 1989;10:211-7.

17 Royal College of General Practitioners, Office of Population Censuses and Surveys. Morbidity statistics from general practice 1981-82. London: HMSO, 1986.

18 Sourk RL, Nugent KM. Bronchodilator testing: confidence intervals derived from placebo inhalations. Am Rev Respir
Dis 1983;128:153-7.

19 Horn CR, Cochrane GM. Management of asthma in general practice. Respir Med 1989;83:67-70.

20 Gross NJ. What is this thing called love? Or defining asthma. Am Rev Respir Dis 1980;121:203-4.

21 Eliasson O, Degraff AC. The use of criteria for reversibility and obstruction to define patient groups for bronchodilator trials. Am Rev Respir Dis 1985;132:858-64.

22 Weir DC, Burge PS. Measures of reversibility in response to bronchodilators in chronic airflow obstruction: relation to airway calibre. Thorax 1991;46:43-5.

23 McCarthy DS, Craig DB, Cherniack RM. Intraindividual variability in maximal expiratory flow-volume and closing volume in asymptomatic subjects. Am Rev Respir Dis 1975;112:407-11.

24 Irving CG, Cherniack RM. Pathophysiology and physiologic assessment of the asthmatic patient. Seminars in Respiratory Medicine 1987;8:201-15.

25 Assessment of airflow obstruction [editorial]. Lancet 1986;ii:1255-6.

26 Kaptein AA, Dekker FW, Gill K, van der Waart MAC. Undertreatment of asthma in Dutch general practice. Fam Pract 1987;4:219-25.

27 Wardman AG, Binns V, Clayden AD, Cooke NJ. The diagnosis and treatment of adults with obstructive airways disease in general practice. British Journal of Diseases of the Chest 1986;80:19-26. 